University of Nebraska - Lincoln

DigitalCommons@University of Nebraska - Lincoln

Faculty Publications, Department of Psychology

Psychology, Department of

November 1999

\title{
Do Mothers and Teens Disagree About Sexual Communication? A Methodological Reappraisal
}

\author{
Marcela Raffaelli \\ University of Nebraska-Lincoln, mraffaelli1@unl.edu \\ Lori A. Smart \\ University of Nebraska-Lincoln \\ Sarah C. Van Horn \\ University of Nebraska-Lincoln \\ Angela D. Hohbein \\ University of Nebraska-Lincoln \\ Jennifer E. Kline \\ University of Nebraska-Lincoln \\ See next page for additional authors
}

Follow this and additional works at: https://digitalcommons.unl.edu/psychfacpub

Part of the Psychiatry and Psychology Commons

Raffaelli, Marcela; Smart, Lori A.; Van Horn, Sarah C.; Hohbein, Angela D.; Kline, Jennifer E.; and Chan, WeiLik, "Do Mothers and Teens Disagree About Sexual Communication? A Methodological Reappraisal" (1999). Faculty Publications, Department of Psychology. 55.

https://digitalcommons.unl.edu/psychfacpub/55

This Article is brought to you for free and open access by the Psychology, Department of at DigitalCommons@University of Nebraska - Lincoln. It has been accepted for inclusion in Faculty Publications, Department of Psychology by an authorized administrator of DigitalCommons@University of Nebraska - Lincoln. 


\section{Authors}

Marcela Raffaelli, Lori A. Smart, Sarah C. Van Horn, Angela D. Hohbein, Jennifer E. Kline, and Wei-Lik Chan 
Published in Journal of Youth and Adolescence, 28 (1999), pp. 395-402. Copyright (C) 1999 Plenum Publishing Corporation/Springer Verlag BV. Used by permission. DOI - 10.1023/A:1021693129479

http://www.springerlink.com/content/u383270701n11748

\title{
Do Mothers and Teens Disagree About Sexual Communication? A Methodological Reappraisal
}

\author{
Marcela Raffaelli, ${ }^{1}$ Lori A. Smart, ${ }^{2}$ Sarah C. Van Horn, ${ }^{3}$ Angela D. Hohbein, ${ }^{4}$ \\ Jennifer E. Kline, ${ }^{5}$ and Wei-Lik Chan ${ }^{6}$
}

Submitted June 1998; accepted January 1999

This study investigated whether parent-teen disagreement in reports of sexual discussions is due to methodological factors. Forty-four mothers and their 12- to 15-yearold daughters $(n=18)$ and sons $(n=26)$ completed parallel questionnaires including measures of communication about 18 different sexual topics during the teen's entire life and during the past year. Analyses examined whether congruence rates were influenced by the use of global as compared to specific items, assessment of conversations during the teen's entire life as compared to the past year, and use of forced-choice as opposed to continuous-response categories. Taken as a whole, results support the notion that methodological limitations are partly responsible for lack of congruence in parent-teen reports. Suggestions for methodological improvements in future research are discussed.

This research was supported in part by a University of Nebraska Research Council Grant-in-Aid to Marcela Raffaelli. The authors acknowledge the research assistance of Sherry Cederberg, Monica Dyer, Amy Gray, and Flor Villasenor, and thank the mothers and teens who participated in the study.

${ }^{1}$ Assistant Professor, Department of Psychology and Institute for Ethnic Studies, University of Nebraska, 238 Burnett Hall, Lincoln, NE 68588-0308; e-mail: mraffaelli1@unl.edu. Received Ph.D. in Psychology (Human Development) from the University of Chicago. Research interests include sociocultural influences on adolescent sexuality and development under conditions of extreme poverty.

${ }^{2}$ Undergraduate Student, Department of Psychology, University of Nebraska, Lincoln. Research interests include parental influences on adolescent sexuality.

${ }^{3}$ Undergraduate Student, Department of Psychology, University of Nebraska, Lincoln. Research interests include child welfare and maltreatment issues.

${ }^{4}$ Undergraduate Student, Department of Psychology, University of Nebraska, Lincoln. Research interests include marital relationships and their influence on other family members.

${ }^{5}$ Undergraduate Student, Department of Psychology, University of Nebraska, Lincoln. Research interests include women's issues, including eating disorders and career-related concerns.

${ }^{6}$ Graduate Student in Industrial/Organizational Psychology, Radford University, Virginia. Research interests center on issues of relevance to expatriates. 


\section{INTRODUCTION}

In recent years, a growing body of literature has demonstrated the importance of parent-teen communication in the socialization of sexual attitudes and behavior (e.g., Casper, 1990; Fisher, 1986; Fox and Inazu, 1980; Holtzman and Rubinson, 1995; Luster and Small, 1994; Moore et al., 1986; Treboux and Busch-Rossnagel, 1990). These findings have led to renewed interest in the role of parents in sexual socialization. However, research that involves both members of the parent-teen dyad has revealed lack of agreement between parents and teens regarding the occurrence and frequency of sexual communication (Smith and Furstenberg, 1994). In a widely cited study, Newcomer and Udry (1985) found substantial disagreement between parents and teens in lifetime reports of sexual discussions. For example, $62 \%$ of mother-son pairs and $71 \%$ of mother-daughter pairs gave identical responses to a question asking whether the mother had ever talked to the teen about premarital sex. The incongruence between parents and teens regarding sexual communication has been regarded as reflecting differences in parent-teen perspectives (e.g., Fisher, 1989; Smith and Furstenberg, 1994). However, a more conservative explanation is that methodological limitations may account for some of the discrepancies between parents and teens. The goal of the current study was to identify methodological factors that might contribute to parent-teen incongruence in reports of sexual discussions.

On the basis of prior research, 3 methodological factors were identified that could contribute to parent-teen discrepancies in reports of sexual discussions. The first factor was the use of global assessment items, which might result in interpretation bias. For example, sexual communication is sometimes assessed with a single item, which may be interpreted differently by parents and teens. Better agreement might result if specific topics are assessed. Support for this expectation can be found in Newcomer and Udry's (1985) study, in which mother-son agreement rates increased from 50\% in response to a global item ("mother has taught things about sex") to $74 \%$ in response to an item regarding discussions of birth control. In the present study, patterns of agreement/disagreement in lifetime reports of discussion about 18 different sexual topics were assessed. It was predicted that higher levels of parent-teen congruence would be observed when dyads were asked about specific as opposed to general topics.

A second potential source of incongruence between parent and teen reports is that researchers often assess communication across the teen's entire life span, raising problems of memory distortions. In the present study, reports of communication during 2 different time periods (lifetime and past year) were compared. We expected to find greater agreement about discussions during the past year than during the teen's entire life span.

A third potential source of methodological error stems from the use of forcedchoice response categories. Forcing respondents to choose between the response options of "ever" and "never" may result in the exaggeration of their differences. It may 
be true that parents report more conversations than teens, but there may be correlations between parent-teen reports that are obscured when the mere presence or absence of discussions is assessed. In their recent study of mother-teen communication about sexual issues, Jaccard et al. (1998) used a 5-point response scale rather than a yes/no format because a "pretest revealed that more sensitivity was required to discriminate different degrees of communication" (p. 252, n. 1), Similarly, the present study assessed frequency of communication in the past year, permitting an examination of the relation between parent and teen reports. We expected to find greater congruence between parents and teens when examining the level rather than the presence/absence of discussions.

\section{METHOD}

\section{Participants}

Forty-four mothers (mean age 40.7; range 31-53 years) and their 12 - to 15 -year-old (mean age 13.8 years) daughters $(n=18)$ and sons $(n=26)$ participated in this study. Mothers were primarily White (96\%), highly educated (all were high school graduates and $37 \%$ were college graduates), and worked outside the home (89\%). Two-thirds were married to the teen's biological father; the remainder were separated (9\%), divorced $(14 \%)$, or in other family types $(11 \%)$.

\section{Procedures}

Participants were recruited using different strategies aimed at obtaining a community sample. Recruitment strategies included mailings to mothers and teens listed in the psychology department's community subject pool (a list of families who had participated in prior research and indicated an interest in hearing about future research possibilities), recruitment from a church confirmation class, and posting of flyers in the general community.

Mothers and teens completed surveys in separate rooms. Mothers provided consent for their own and their child's participation; teens completed a separate assent form. Mothers and teens completed parallel questionnaires focusing on different aspects of sexual communication and their general relationship. Each mother-teen pair was paid $\$ 10$.

\section{Measures}

This analysis draws on measures of communication about 18 different sexual topics during 2 time periods: the teen's entire life and the past year (see Table I for a list of topics). Lifetime communication was assessed on a 3-point scale (yes/no/don't know) 
Table I. Patterns of Agreement/Disagreement About Lifetime Discussions by Topic ( $N=44$ Mother-Teen Dyads)

\begin{tabular}{lrrrr}
\hline \multicolumn{4}{c}{ Congruent } & \\
\cline { 2 - 4 } \multicolumn{1}{c}{ Topic } & Both & Both No or & \\
\cline { 2 - 4 } & Yes & Don't know & All & Incongruent \\
\hline Dating and boyfriends/girlfriends & 84.1 & 0 & 84.1 & 15.9 \\
Sex (pregnancy and intercourse) & 54.5 & 4.5 & 59.1 & 40.9 \\
What physically happens during sex & 6.8 & 38.6 & 45.5 & 54.5 \\
Menstruation and the menstrual cycle & 39.5 & 20.9 & 60.5 & 39.5 \\
How a girl can tell if she is pregnant & 9.3 & 46.5 & 55.8 & 44.2 \\
At what point in the menstrual cycle it is & 4.5 & 61.4 & 65.9 & 34.1 \\
$\quad$ easiest for a girl to get pregnant & & & & \\
Birth control & 13.6 & 18.2 & 31.8 & 68.2 \\
How you would use different types & 2.3 & 59.1 & 61.4 & 38.6 \\
Where you can get the different types & 2.3 & 48.8 & 51.2 & 48.8 \\
Who should take primary responsibility & 11.4 & 38.6 & 50.0 & 50.0 \\
Dangers or risks of AIDS/HIV/other STDs & 65.9 & 6.8 & 72.7 & 27.3 \\
How you can get STDs & 52.3 & 11.4 & 63.6 & 36.4 \\
How you can protect yourself against STDs & 36.4 & 15.9 & 52.3 & 47.7 \\
Indications or signs that you might have an STD & 4.5 & 68.2 & 72.7 & 27.3 \\
Whether premarital sex is okay & 41.9 & 2.3 & 44.2 & 55.8 \\
Under what circumstances it is acceptable & 22.7 & 25.0 & 47.7 & 52.3 \\
$\quad$ for teens your age to have sex & & & & \\
Religious beliefs relating to premarital sex & 15.9 & 36.4 & 52.3 & 47.7 \\
How your mother would react if she & 18.2 & 36.4 & 54.5 & 45.5 \\
found out you had sex & & & & \\
\hline
\end{tabular}

indicating if the topic had ever been discussed during the teen's lifetime. Communication during the past year was assessed on a 5 -point scale $(1=$ never, $2=1-2$ times, $3=$ 3-5 times, $4=6-10$ times, $5=$ more than 10 times).

\section{Analyses}

Mother and teen responses on each question were cross tabulated to look at patterns of agreement and disagreement. If both gave the same response, the dyad was considered congruent (i.e., yes/yes, no/no, don't know/don't know); if responses differed, the dyad was considered incongruent. The proportion of dyads classified as congruent or incongruent on each topic then was compared.

\section{RESULTS AND DISCUSSION}

The proportion of mother-teen dyads who gave congruent responses regarding whether each topic had been discussed during the teen's lifetime is shown in Table I. There was wide variation in the proportion of congruent responses, ranging from a 
low of $31.8 \%$ on the general "birth control" item to a high of $84.1 \%$ on the "dating and boyfriends/girlfriends" item. This variation suggests the need to examine specific topics separately. Examination of the birth control items supports the prediction that more parents and teens would give congruent reports when asked about specific as opposed to general topics. Agreement rates for the 3 specific birth control items (how to use, where to get, and who should take primary responsibility) were higher than for the general "birth control" item. These higher congruence rates were due in large part to mother-teen agreement that these 3 topics had not been discussed.

The next issue to be examined was whether congruence was influenced by the time period of measurement. Table II shows the proportion of mother-teen dyads giving congruent responses (i.e., both said "yes," both said "no," or both said "don't know") regarding discussion of each topic during the teen's lifetime and past year. Statistical differences in the proportion of congruent pairs in each time period was assessed using the test for the difference between proportions (Loether and McTavish, 1974). Although few of the comparisons were statistically significant, there was a general pat-

Table II. Percentage of Mother-Teen Dyads Who Gave Congruent Responses by Time Period and Topic of Discussion

\begin{tabular}{lcc}
\hline & \multicolumn{2}{c}{ Time Period of Discussion } \\
\cline { 2 - 3 } \multicolumn{1}{c}{ Topic } & Lifetime & Past Year \\
\hline Dating and boyfriends/girlfriends & 84.1 & 93.2 \\
Sex (pregnancy and intercourse) & 59.1 & 65.1 \\
What physically happens during sex & 45.5 & 56.8 \\
Menstruation and the menstrual cycle & 60.5 & 70.7 \\
How a girl can tell if she is pregnant & 55.8 & 69.8 \\
At what point in the menstrual cycle is it & 65.9 & $90.7^{a}$ \\
$\quad$ easiest for a girl to get pregnant & & \\
Birth control & 31.8 & $54.5^{a}$ \\
How you would use different types & 61.4 & 72.1 \\
Where you can get different types & 51.2 & $70.5^{b}$ \\
Who should take primary responsibility & 50.0 & 55.8 \\
Dangers or risks of AIDS/HIV/other STDs & 72.7 & 74.4 \\
How you can get STDs & 63.6 & 55.8 \\
How you can protect yourself against STDs & 52.3 & 50.0 \\
Indications or signs of an STD & 72.7 & 72.1 \\
Whether premarital sex is okay & 44.2 & 50.0 \\
Under what circumstances it is acceptable & 47.7 & 53.5 \\
$\quad$ for teens your age to have sex & & \\
Religious beliefs relating to premarital sex & 52.3 & 62.8 \\
How your mother would react if she found & 54.5 & 65.9 \\
$\quad$ out you had sex & & \\
\hline a $p<$ \& .05. & & \\
${ }^{p} p<.10$. & & \\
\end{tabular}


tern of greater congruence regarding communication during the past year as opposed to across the teen's lifetime. The proportion of congruent dyads increased by under $10 \%$ for 6 items, by between 10 and $15 \%$ for 6 items, and by over $15 \%$ for 3 items. Thus, limiting the reporting time span to the past year appeared to increase parent-teen agreement about their sexual discussions. Interestingly, all 3 topics that showed decreased or unchanged parent-teen congruence related to STDs; the reason for this pattern is unclear.

The third question was whether use of a dichotomous outcome variable (i.e., presence/absence of discussion about each topic) concealed an underlying relation that might be revealed by examining a more differentiated outcome measure. In this analysis, mother and teen reports of frequency of discussion in the past year on a 5-point scale were compared using paired t-tests, and the correlation between mother and teen scores was compared. Because preliminary analyses showed significant gender differences in mean levels of sexual communication, analyses were conducted separately for males and females.

As can be seen in Table III, there was a fair amount of variation in mean levels of reported communication among mother-son pairs, with 4 of the comparisons reaching

Table III. Mean Differences and Correlations Between Mother-Son and Mother-Daughter Pairs ${ }^{a}$ in Reported Frequency of Discussion in Past Year

\begin{tabular}{|c|c|c|c|c|c|c|}
\hline Topic & Mother & Son & $r^{b}$ & Mother & Daughter & $r^{b}$ \\
\hline Dating and boyfriends/girlfriends & 3.15 & 2.92 & $.601^{c}$ & 3.78 & 3.50 & .194 \\
\hline Sex (pregnancy and intercourse) & 2.20 & 1.76 & -.042 & 2.67 & 2.33 & .179 \\
\hline What physically happens during sex & 1.23 & 1.19 & -.036 & 1.44 & 1.72 & -.124 \\
\hline Menstruation/menstrual cycle & 1.50 & $1.13^{d}$ & .109 & 3.41 & 3.24 & .322 \\
\hline How a girl can tell if she is pregnant & 1.08 & 1.19 & -.089 & 1.88 & 1.59 & .196 \\
\hline $\begin{array}{l}\text { At what point in the menstrual cycle it } \\
\text { is easiest for a girl to get pregnant }\end{array}$ & 1.00 & 1.00 & - & 1.39 & 1.33 & .234 \\
\hline Birth control & 1.73 & $1.15^{d}$ & -.096 & 1.83 & 1.56 & .186 \\
\hline How to use different types & 1.46 & $1.04^{d}$ & $.387^{d}$ & 1.47 & 1.41 & .187 \\
\hline Where to get different types & 1.35 & $1.00^{d}$ & - & 1.39 & 1.39 & -.070 \\
\hline Who should take primary responsibility & 1.81 & $1.31^{a}$ & -.172 & 1.47 & 1.53 & -.088 \\
\hline Dangers or risks of AIDS/HIV/STDs & 2.73 & 2.42 & .112 & 2.88 & 2.76 & .134 \\
\hline How you can get STDs & 2.15 & 1.85 & -.017 & 2.41 & 2.12 & .220 \\
\hline How you can protect against STDs & 2.08 & 1.69 & .026 & 2.00 & 1.72 & .113 \\
\hline Indications that you might have an STD & 1.24 & 1.20 & .187 & 1.44 & 1.44 & .199 \\
\hline Whether premarital sex is okay & 2.35 & $1.85^{e}$ & .090 & 2.39 & 2.28 & .228 \\
\hline $\begin{array}{l}\text { Under what circumstances it is } \\
\text { acceptable for teens to have sex }\end{array}$ & 1.81 & 1.62 & -.035 & 2.24 & 2.12 & .283 \\
\hline Religious beliefs & 2.08 & 1.69 & $.612^{c}$ & 1.65 & 1.47 & $.854^{c}$ \\
\hline $\begin{array}{l}\text { How your mother would react if she } \\
\text { found out you had sex }\end{array}$ & 1.35 & 1.62 & .106 & 1.67 & 2.11 & .219 \\
\hline
\end{tabular}

${ }^{a} N=26$ mother-son pairs and 18 mother-daughter pairs.

${ }^{b}$ Significance tests based on paired $t$-tests.

${ }^{c} p<.001$.

${ }^{d} p<.05$.

$e p<.10$. 
statistical significance $(p<.05)$ and 2 reaching marginal significance $(p<.10)$. In all cases, mothers reported higher levels of communication than sons. Only 3 of the correlations between mother and son reports reached statistical significance; the remaining correlations were under .20. In contrast, none of the comparisons in mean levels of sexual discussions between mother-daughter pairs were significant. Only one of the mother-daughter correlations reached statistical significance, although 6 of the 18 correlations exceeded 20 .

This analysis suggests that mother-daughter pairs do not differ in reports of sexual communication to the same degree as mother-son pairs, although the lack of correlation between mother and daughter scores suggests only modest correspondence. Note that incongruence between parents and teens is not limited to research on sexual issues; research examining other relationship aspects has shown similarly modest correlations. For example, in an examination of parent-child correspondence in reports of family communication patterns, Tims and Masland (1985) found correlations between .12 and .19 on single items, and of .30 on a 3-item index. Similarly, correlations between child and parent reports on measures of parental control, support, and participation ranged from .05 to .41 , with the majority falling into the low-to-modest range (Gecas and Schwalbe, 1986). Thus, the issue of how large a correlation indicates "good" agreement remains an open question.

\section{CONCLUSIONS}

The goal of this study was to investigate whether the widely reported find $\neg$ ing that parents and teens disagree in reports of sexual discussions are due in part to methodological factors. Based on prior research, 3 methodological factors that might have contributed to the incongruence reported in prior research were identified: the use of global items; assessment across the teen's entire lifespan; and forced-choice response categories. These 3 methodological factors were examined in the present analysis.

Taken as a whole, the findings support the premise that methodological limitations are partly responsible for lack of congruence in parent-teen reports, and suggest ways in which instruments can be improved in future research. First, it appears that asking specific questions will elicit greater agreement between reporters, presumably because interpretation biases will be diminished. In addition, researchers should investigate what meanings study participants attribute to questionnaire items, rather than assuming that they interpret them similarly (Jaccard and Dittus, 1993). Second, researchers could ask about specific time periods. In the current study, there was a pattern for greater parent-teen agreement when responding to items about conversations in the past year rather than across the teen's entire life span. It is likely that limiting the response period to less than a year will result in higher agreement rates. Third, continuous response as opposed to forced-choice response scales could be used. In the current study, mothers reported higher levels of communication about most topics than their 
teenage children; however, none of the paired comparisons were significant for girls (suggesting an overall pattern of agreement) and only one-third of the comparisons were significant for boys. These findings suggest underlying agreement despite different perceptions of the level of conversations.

Despite the small sample size, this study revealed that methodological factors do influence parent-teen reports of sexual discussion. Research on parent-teen communication regarding sexual topics would benefit from a focus on methodological issues. Although it is probably true that parents and teens differ considerably in how they experience and perceive sexual discussions, methodological limitations in existing measures probably exaggerate those differences. Until valid and reliable ways of assessing communication are developed, researchers will be unable to obtain an accurate picture of parent-teen communication about sex and understand the effect of parental sexual socialization on teen sexuality.

\section{REFERENCES}

Casper, L. M. (1990). Does family interaction prevent adolescent pregnancy. Fam. Plann. Perspect. 22: $109-114$.

Fisher, T. D. (1986). Parent-child communication about sex and young adolescents' sexual knowledge and attitudes. Adolescence 21: 517-527.

Fisher, T. D. (1989). An extension of the findings of Moore, Peterson, and Furstenberg (1986) regarding family sexual communication and adolescent sexual behavior. J. Marr. Fam. 51: 637-639.

Fox, G. L., and Inazu, J. K. (1980). Patterns and outcomes of mother-daughter communication about sexuality. J. Soc. Issues 36: 7-29.

Gecas, V., and Schwalbe, M. L. (1986). Parental behavior and adolescent self-esteem. J. Marr.Fam. 48: 37-46.

Holtzman, D., and Rubinson, R. (1995). Parent and peer communication effects on AIDS-related behavior among U.S. high school students. Fam. Plann. Perspect. 27: 235-268.

Jaccard, J., and Dittus, P. J. (1993). Parent-adolescent communication about premarital pregnancy. Fam. Society. 74: 329-343.

Jaccard, J., Dittus, P. J., and Gordon, V. V. (1998). Parent-adolescent congruency in reports of adolescent sexual behavior and in communications about sexual behavior. Child Develop. 69: 247-261.

Loether, H., and McTavish, D. (1974). Inferential Statistics for Sociologists. Allyn \& Bacon, Boston.

Luster, T., and Small, S. A. (1994). Factors associated with sexual risk-taking behaviors among adolescents. J. Marr. Fam. 56: 622-632.

Moore, K. A., Peterson, J. L., and Furstenberg, F. F. (1986). Parental attitudes and the occurrence of early sexual activity. J. Marr. Fam. 48: 777-782.

Newcomer, S. F., and Udry, J. R. (1985). Parent-child communication and adolescent sexual behavior. Fam. Plann. Perspect. 17: 169-174.

Smith, H. L., and Furstenberg, F. F. (1994). Application of a response model for mother-daughter agreement by race. Soc. Sci. Res. 23: 136-166.

Tims, A. R., and Masland, J. L. (1985). Measurement of family communication patterns. Commun. Res. 12: 35-57.

Treboux, D., and Busch-Rossnagel, N. A. (1990). Social network influences on adolescent sexual attitudes and behaviors. J. Adolesc. Res. 5: 175-189. 